\title{
Metabolic engineering of a reduced-genome strain of Escherichia coli for L-threonine production Jun Hyoung Lee ${ }^{\dagger 1}$, Bong Hyun Sung ${ }^{\dagger 1}$, Mi Sun Kim², Frederick R Blattner ${ }^{3,4}$, Byoung Hoon Yoon ${ }^{1}$, Jung Hoe Kim ${ }^{1}$ and Sun Chang Kim*1
}

\author{
Address: ${ }^{1}$ Department of Biological Sciences, Korea Advanced Institute of Science and Technology, Daejeon 305-701, Korea, ${ }^{2 B i o m a s s ~ T e a m, ~ K o r e a ~}$ \\ Institute of Energy Research, Daejeon 305-343, Korea, ${ }^{3}$ Department of Genetics, University of Wisconsin, Madison, Wisconsin 53706, USA and \\ ${ }^{4}$ Scarab Genomics, Madison, Wisconsin 53713, USA \\ Email: Jun Hyoung Lee - junhlee@kaist.ac.kr; Bong Hyun Sung - bonhoney@kaist.ac.kr; Mi Sun Kim - bmmskim@kier.re.kr; \\ Frederick R Blattner - fred@genome.wisc.edu; Byoung Hoon Yoon - yoonbh@kaist.ac.kr; Jung Hoe Kim - kimjh@kaist.ac.kr; \\ Sun Chang Kim* - sunkim@kaist.ac.kr \\ * Corresponding author †Equal contributors
}

Published: 7 January 2009

Microbial Cell Factories 2009, 8:2 doi:10.1 186/1475-2859-8-2
Received: 22 October 2008

Accepted: 7 January 2009

This article is available from: http://www.microbialcellfactories.com/content/8/I/2

(C) 2009 Lee et al; licensee BioMed Central Ltd.

This is an Open Access article distributed under the terms of the Creative Commons Attribution License (http://creativecommons.org/licenses/by/2.0), which permits unrestricted use, distribution, and reproduction in any medium, provided the original work is properly cited.

\begin{abstract}
Background: Deletion of large blocks of nonessential genes that are not needed for metabolic pathways of interest can reduce the production of unwanted by-products, increase genome stability, and streamline metabolism without physiological compromise. Researchers have recently constructed a reduced-genome Escherichia coli strain MDS42 that lacks I4.3\% of its chromosome.

Results: Here we describe the reengineering of the MDS42 genome to increase the production of the essential amino acid L-threonine. To this end, we over-expressed a feedback-resistant threonine operon $(t h r A B C)$, deleted the genes that encode threonine dehydrogenase $(t d h)$ and threonine transporters ( $t d c C$ and sstT), and introduced a mutant threonine exporter (rhtA23) in MDS42. The resulting strain, MDS-205, shows an $83 \%$ increase in L-threonine production when cells are grown by flask fermentation, compared to a wild-type E. coli strain MGI655 engineered with the same threonine-specific modifications described above. And transcriptional analysis revealed the effect of the deletion of non-essential genes on the central metabolism and threonine pathways in MDS-205.
\end{abstract}

Conclusion: This result demonstrates that the elimination of genes unnecessary for cell growth can increase the productivity of an industrial strain, most likely by reducing the metabolic burden and improving the metabolic efficiency of cells.

\section{Background}

The vast increase in annotated genome information and high-throughput technologies has enabled a systematic improvement of industrial microbes through genome engineering. Restructuring of microbial genomes has been shown to have several advantages over conventional approaches for strain improvement [1-5]. Restructured genomes with the desired functionalities have served as customized industrial strains that display (i) streamlined metabolic pathways for the production of selected biomaterials, (ii) a reduced production of unwanted by-products, and (iii) increased genome stability [6-9]. 
Escherichia coli is the most commonly used microbe for both laboratory research and industrial-scale production of metabolites, such as amino acids and proteins, for therapeutic or commercial uses [10-14]. Because E. coli has adapted to a lifestyle that includes residence in animal intestines with frequent exposure to aqueous and soil environments, many of the genes in its genome are unnecessary for growth in the relatively simple environment within industrial fermentors. Further, the complete genome sequence of $E$. coli has revealed numerous genes whose products have no known functions and genetic materials that may have been acquired from other organisms in the recent past [15]. In an effort to improve E. coli as an industrial host, many researchers have deleted or added limited numbers of selected genes to the genome or modified plasmids to complement the existing genome [16-24]. These efforts have helped researchers make significant progress in improving E. coli as a production host, but have not addressed the productivity problems caused by the numerous $E$. coli genes with potentially detrimental functions.

Recently, an E. coli genome was reduced by the precise deletion of nonessential genes and other DNA sequencesincluding all known recombinogenic and mobile DNA and cryptic virulence genes-to construct a genetically stable strain that displays robust metabolic performance [5]. The resulting strain, E. coli MDS42, has a chromosome that is $14.3 \%$ smaller than that of its parental E. coli strain MG1655. MDS42 shows robust growth under normal laboratory conditions and even better growth in high-cell density fermentations, as well as increased transformation efficiency relative to MG1655 [5]. Therefore, the elimination of unnecessary genes and sequences from an E. coli genome appears to have produced a stable reducedgenome strain without physiological compromise. Furthermore, the deletion of all insertion sequence (IS) ele- ments from the genome means that the strain is free of ISmediated mutagenesis and genomic rearrangements.

In this study, we report the results of a reengineering of MDS42 to increase production of the amino acid L-threonine, which is essential for growth and maintenance of commercial livestock [25]. This reengineering included the overexpression of a feedback-resistant threonine operon $\left(t h r A^{*} B C\right)$ under the control of a recombinant Tac promoter, deletion of the genes that encode threonine dehydrogenase $(t d h)$ and threonine uptake proteins ( $t d c C$ and sst T), and introduction of a mutant threonine exporter gene (rhtA23). The reengineered strain, called MDS-205, shows an $\sim 83 \%$ increase in threonine production by flask fermentation relative to the wild-type E. coli strain MG1655 that had been engineered to carry the same threonine-specific modifications. Minimization of an $E$. coli genome by the elimination of genes unnecessary for growth increases the productivity of the strain by reducing the metabolic burden caused by maintenance and expression of unnecessary genes and improving the metabolic efficiency of the cell.

\section{Methods \\ Bacterial strains, plasmids, enzymes, and chemicals}

The bacterial strains used in this work are listed in Table 1. Plasmid pKD46 was obtained from B. L. Wanner [26], pST76-ASceP from G. Posfai [27], and pCSI from S. C. Kim [28]. All enzymes were purchased from New England Biolabs (Beverly, MA, USA) except Taq polymerase, which was from Takara Bio Inc. (Shiga, Japan). All antibiotics and chemicals were from Sigma-Aldrich (St. Louis, MO, USA). Ampicillin, chloramphenicol, and kanamycin were used at concentrations of 50,17, and $25 \mu \mathrm{g} / \mathrm{ml}$, respectively. All the primers used in this work are listed in Additional file 1.

Table I: $E$. coli strains used in this study

\begin{tabular}{|c|c|c|}
\hline Strain name & Description & Source or reference \\
\hline MGI655 & $\lambda$-F-ilvG rfb-50 rph-l & Blattner et al. (1997) \\
\hline MG-I02 & MGI $655 P_{T a c}-$ thrA*BC $\Delta$ lacl & This study \\
\hline MG-103 & MGI $655 P_{T a c}-t h r A^{*} B C \Delta l a c l \Delta t d h$ & This study \\
\hline MG-I04 & MGI $655 P_{T a c}-t h r A * B C \Delta l a c l \Delta t d h \Delta t d c C:: r h t A 23$ & This study \\
\hline MG-I05 & MGI $655 P_{T a c}-t h r A * B C$ Alacl $\Delta t d h \Delta t d c C:: r h t A 23 \Delta s s t T:: r h t A 23$ & This study \\
\hline MDS42 & Reduced genome strain & Posfai et al. (2006) \\
\hline MDS-202 & MDS42 $P_{T a c}-t h r A * B C$ slacl & This study \\
\hline MDS-203 & MDS42 $P_{T a c}-t h r A * B C \Delta l a c l \Delta t d h$ & This study \\
\hline MDS-204 & MDS42 $P_{T a c}-t h r A * B C \Delta l a c l \Delta t d h \Delta t d c C:: r h t A 23$ & This study \\
\hline MDS-205 & MDS42 $P_{T a c}-t h r A * B C \Delta l a c l \Delta t d h \Delta t d c C:: r h t A 23 \Delta s s t T:: r h t A 23$ & This study \\
\hline MGI655 thrB::Tn5 & MGI655 thrB::Tn5 & Yu et al. (2002) \\
\hline N99 rhtA23 & W3350 rpsL rhtA23 thr::TnIO & Livshits et al. (2003) \\
\hline E. coli ATCC 21277 & K-I 2 SupE relA ${ }^{+} K m^{R}-P_{T A C}-t h r A^{*} B C$ ilvA422 & Shiio et al. (197I) \\
\hline
\end{tabular}




\section{Construction of threonine-producing E. coli strains}

To study the effect of minimization of an E. coli genome on the production of L-threonine, the reduced-genome strain MDS42 [5] and wild-type strain MG1655 were engineered to produce L-threonine. First, to release the feedback inhibition on aspartokinase I and homoserine dehydrogenase I that are encoded by the thrA gene, and the transcriptional attenuation of the thrABC operon by intracellular threonine [29], a feedback-resistant $t h r A^{*} B C$ operon under the control of a Tac promoter [30] was introduced to replace the wild-type thrABC operon in the MG1655 and MDS42 genomes (Fig. 1). The feedbackresistant $t h r{ }^{*} B C$ operon $(3.5 \mathrm{~kb})$ was amplified by the polymerase chain reaction (PCR) from E. coli ATCC
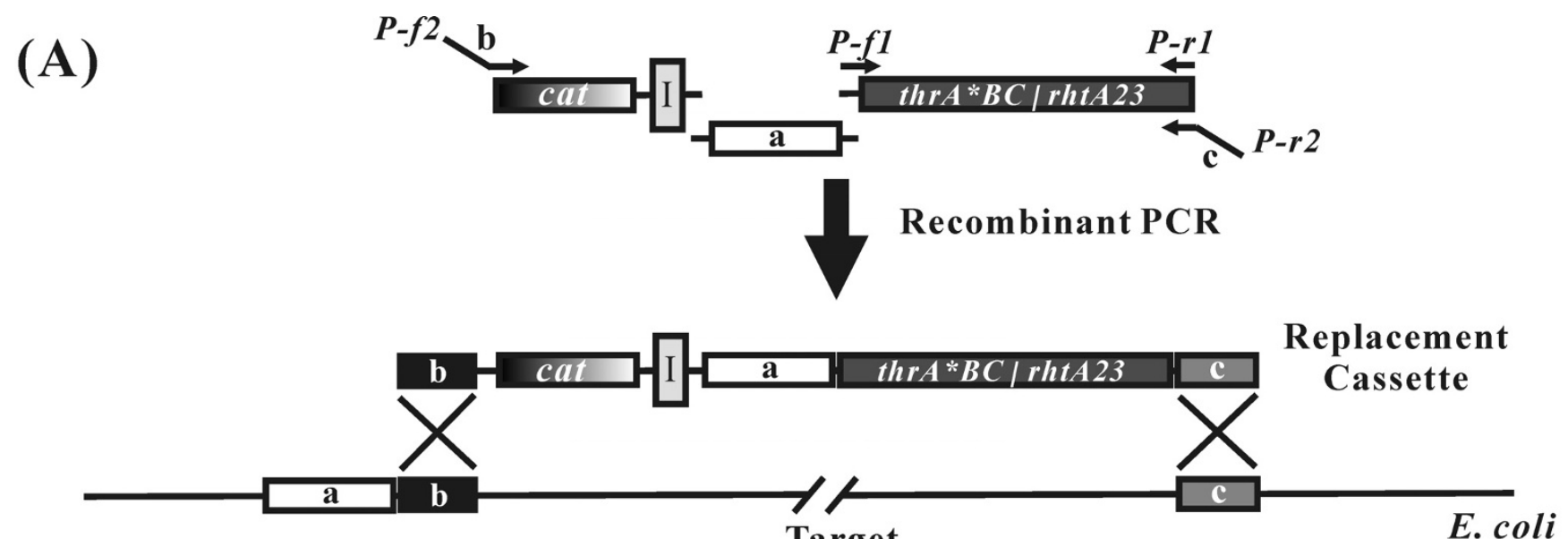

Target

genome

(B)

$\int$ Homologous recombination

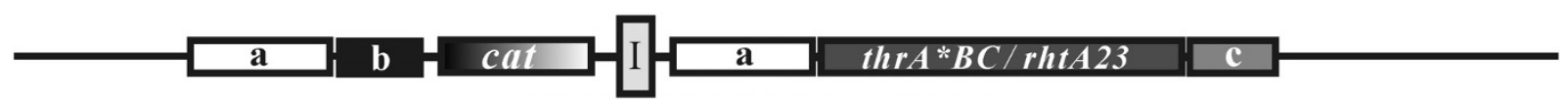

Cleavage by I-SceI

(C)
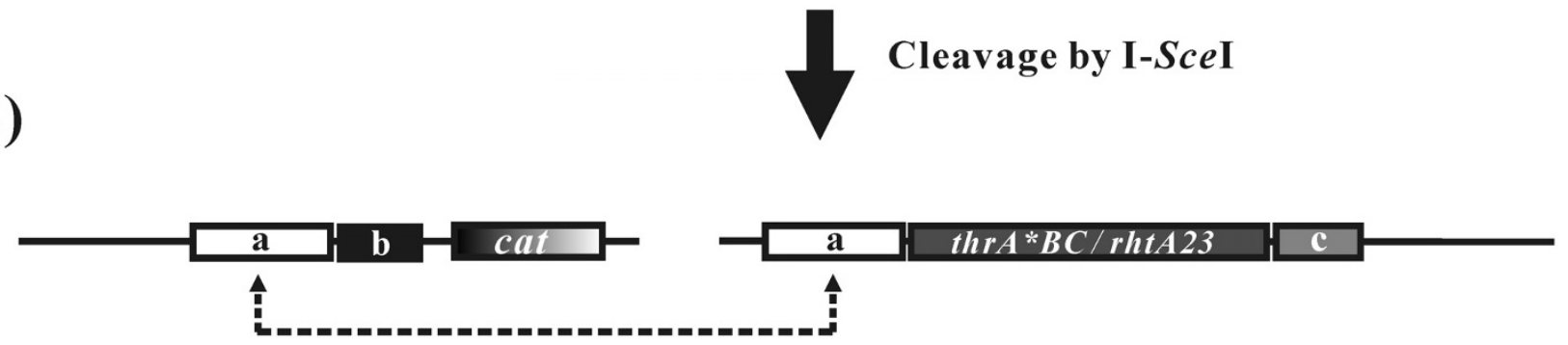

$\downarrow$ Doublestranal hereak repir

Figure I

Markerless replacement of a target. (A) A linear DNA cassette containing a positive selection marker (cat), an I-Scel recognition site (I), a gene to be replaced (thrA*BC or rhtA23), and three homology arms (represented as a, b, and c) were amplified by recombinant PCR (refer to Materials and Methods). PCR primers are labeled with lower case, italicized letters $(P-f l, P$ $r l, P-f 2$, and $P-r 2$ ) and arrows. (B) The target of the $E$. coli genome was replaced by the constructed DNA cassette, and recombinants were selected on LB plates containing chloramphenicol. (C) The cat gene introduced was excised from the selected recombinants by double-strand break repair mediated by I-Scel cleavage. 
21277 genomic DNA with the following forward (P-f1) and reverse (P-r1) primers (see Fig. 1). A 1.2-kb fragment containing a chloramphenicol resistant gene (cat) and an I-SceI recognition site was also amplified by PCR from plasmid pCSI [28]. Finally, a 0.5-kb homology fragment that sits to the left of the thrABC operon (Fig. 1a) was PCRamplified from the chromosomal DNA of MDS42 and MG1655. This amplified 0.5-kb fragment contained a short, 20-base pair (bp) flanking sequence on each side: the $3^{\prime}$ end of the $0.5-\mathrm{kb}$ fragment overlapped with the 5 ' end of the 3.5-kb fragment and the 5 ' end overlapped with the 3 ' end of the 1.2-kb fragment described above. This 0.5 -kb fragment and 2 PCR fragments above (that is, the 3.5-kb PCR fragment, which contained the feedbackresistant $t h r A^{*} B C$ operon under the control of a Tac promoter, and the 1.2-kb fragment, which contained a cat gene and an I-SceI recognition site) were combined by recombinant PCR using the following forward (P-f2) and reverse (P-r2) primers (see Fig. 1A). The constructed 5.3kb DNA cassette was electrotransformed into MG1655 and MDS42, both of which harbored pKD46 expressing $\lambda$ Red genes $(\gamma, \beta$, and exo). The recombinants were selected on chloramphenicol-containing LB plates, and then the helper plasmid pKD46 was cured by growing the selected recombinants at $42^{\circ} \mathrm{C}$. The cat gene that was introduced as described above was then excised from the constructed recombinant strains by double-strand break (DSB) repair mediated by the I-SceI endonuclease expressed from pST76-ASceP, which generated strain MG-101 from MG1655 and strain MDS-201 from MDS42. To constitutively express the feedback-resistant $t h r{ }^{*} B C$ operon under the control of a Tac promoter, the lacI gene was deleted from the MG-101 and MDS-201 genomes by the markerless deletion method [28], producing MG-102 and MDS-202, respectively. To prevent the degradation of Lthreonine produced inside the cells, the threonine dehydrogenase gene $(t d h)$ was deleted from the MG-102 and MDS-202 genomes by the markerless deletion method, generating strains MG-103 and MDS-203, respectively. To further increase threonine production, two threonine uptake genes, $t d c C$ and $s s t T$, were sequentially replaced by the mutant threonine exporter gene (rhtA23) (see Fig. 1), whose expression level is 10 -fold higher than that of the wild-type rhtA gene [31]. These manipulations yielded strains MG-104 and MG-105 from MG-103, and MDS204 and MDS-205 from MDS-203. At each step of the strain constructions, the modification of each target region was verified by PCR using pairs of primers that flanked the endpoints of each target region.

\section{Bioassay for L-threonine using an E. coli threonine auxotroph}

The threonine auxotroph MG1655 thrB::Tn5 [32] was inoculated into $3 \mathrm{ml}$ of LB medium supplemented with kanamycin and grown at $37^{\circ} \mathrm{C}$. When the $\mathrm{OD}_{600}$ reached
0.8 , the threonine auxotrophic cells were harvested by centrifugation at $6,000 \mathrm{~g}$ for $10 \mathrm{~min}$, resuspended in $3 \mathrm{ml}$ of fresh M9 minimal medium, and cultivated for $5 \mathrm{~h}$ at $37^{\circ} \mathrm{C}$ to deplete any endogenous threonine available to the cells [33]. The threonine auxotrophic culture was then diluted 1:100 into $3 \mathrm{ml}$ of fresh M9 minimal medium to which $300 \mu \mathrm{l}$ of the filterate of the culture broth of each threonine producing strains was added. After $24 \mathrm{~h}$ of cultivation at $37^{\circ} \mathrm{C}$, growth of the threonine auxotroph was measured at $\mathrm{OD}_{600}$.

A standard growth curve was established in order to correlate the growth of the auxotroph to various concentrations of threonine in M9 minimal media. Linear regression analysis of the plotted data was considered a least-squares fit $\left(\mathrm{R}^{2}\right)$ of the relationship between threonine supplementation and growth of the auxotroph, and was used as a standard curve when $\mathrm{R}^{2}$ was greater than 0.95 . The $\mathrm{R}^{2}$ value was derived from the regression line of the resulting plots $\left(\mathrm{OD}_{600}\right.$ vs. threonine concentration).

\section{Threonine production by flask fermentation}

The threonine-producing strains were grown on LB plates overnight and then transferred to a $250 \mathrm{ml}$ flask containing $50 \mathrm{ml}$ of seed medium [32.5 g glucose, $24.35 \mathrm{~g}$ $\mathrm{K}_{2} \mathrm{HPO}_{4}, 9.5 \mathrm{~g} \mathrm{KH}_{2} \mathrm{PO}_{4}, 15$ g yeast extract, $5 \mathrm{~g}\left(\mathrm{NH}_{4}\right)_{2} \mathrm{SO}_{4}$, $1 \mathrm{~g} \mathrm{MgSO}_{4} \cdot 7 \mathrm{H}_{2} \mathrm{O}$ per liter at $\left.\mathrm{pH} 7.0\right]$. After growing the culture for $24 \mathrm{~h}$ at $37^{\circ} \mathrm{C}$, an aliquot $(1 \mathrm{ml})$ of the seed culture was transferred to $50 \mathrm{ml}$ of fermentation medium-1 [ 2 g yeast extract, $2 \mathrm{~g}$ citric acid, $25 \mathrm{~g}\left(\mathrm{NH}_{4}\right)_{2} \mathrm{SO}_{4}, 7.46 \mathrm{~g}$ $\mathrm{KH}_{2} \mathrm{PO}_{4}, 40$ g glucose, $2 \mathrm{~g} \mathrm{MgSO}_{4} \cdot 7 \mathrm{H}_{2} \mathrm{O}, 5 \mathrm{mg} \mathrm{FeSO} \cdot \cdot 7$ $\mathrm{H}_{2} \mathrm{O}, 5 \mathrm{mg} \mathrm{MnSO}_{4} \cdot 4 \mathrm{H}_{2} \mathrm{O}$, and $20 \mathrm{~g} \mathrm{CaCO}_{3}$ per liter at $\mathrm{pH}$ 7.2]. The fermentation was run for $24 \mathrm{~h}$ at $37^{\circ} \mathrm{C}$, with vigorous agitation of the culture on a shaker (300 rpm). After cultivation, the amount of threonine accumulated in the broth was analyzed with the bioassay system using the threonine auxotroph described above.

\section{Threonine production by batch fermentation}

MDS-205 was grown in a 2-liter jar fermentor containing 1.5 liters of fermentation medium-2 [100 g glucose, $10 \mathrm{~g}$ $\left(\mathrm{NH}_{4}\right)_{2} \mathrm{SO}_{4}, 2 \mathrm{~g} \mathrm{KH}_{2} \mathrm{PO}_{4}, 0.5 \mathrm{~g} \mathrm{MgSO}_{4} \cdot 7 \mathrm{H}_{2} \mathrm{O}, 5 \mathrm{mg}$ $\mathrm{FeSO}_{4} \cdot 7 \mathrm{H}_{2} \mathrm{O}, 5 \mathrm{mg} \mathrm{MnSO}{ }_{4} \cdot 4 \mathrm{H}_{2} \mathrm{O}$, and 3 g yeast extract per liter at $\mathrm{pH}$ 7.5]. A seed culture was grown for $12 \mathrm{~h}$ at $37^{\circ} \mathrm{C}$ in a $500 \mathrm{ml}$ flask containing $75 \mathrm{ml}$ of seed medium and then inoculated into the 2-liter jar fermentor. During batch phase fermentation, the $\mathrm{pH}$ was maintained at 7.5 with $\mathrm{NH}_{4} \mathrm{OH}$, the temperature at $37^{\circ} \mathrm{C}$, the aeration rate at $1 \mathrm{vvm}$ (air volume -working volume $\mathrm{e}^{-1} \cdot \mathrm{min}^{-1}$ ), and the agitation speed at $800 \mathrm{rev} / \mathrm{min}$. After $30 \mathrm{~h}$ of fermentation, the concentration of threonine was determined by pre-column derivation with OPA (o-phthaldehyde-thiol) using the method developed by Joseph and Marsden [34] with the following modifications. Threonine was analysed on a Micra NPS ODS-1 $(33 \mathrm{~mm} \times 4.6 \mathrm{~mm}) 1.5-\mu \mathrm{m}$ 
column (Eichrom Technologies, IL, USA) in reversed phase with a concentration gradient of sodium acetate buffer. This gradient was formed from two buffers, 100 $\mathrm{mM}$ sodium acetate, pH 5.9 (adjusted with $1 \mathrm{M} \mathrm{HCl}$; buffer A) and pure methanol (buffer B), with a flow rate of $0.5 \mathrm{ml} / \mathrm{min}$. The time course of the gradient was as follows: the starting point, buffer A/buffer B $(98: 2, \mathrm{v} / \mathrm{v}) ; 1$ min, A/B $(85: 15, \mathrm{v} / \mathrm{v}) ; 5 \mathrm{~min}, \mathrm{~A} / \mathrm{B}(50: 50, \mathrm{v} / \mathrm{v}) ; 10 \mathrm{~min}, \mathrm{~A} /$ $\mathrm{B}(30: 70, \mathrm{v} / \mathrm{v}) ; 18 \mathrm{~min}, \mathrm{~A} / \mathrm{B}(2: 98, \mathrm{v} / \mathrm{v})$. The retention times and response factors of the threonine were evaluated by injecting known amounts of L-threonine.

\section{Microarray analysis}

Strains MG1655, MDS42, MG-105, and MDS-205 were inoculated from single colonies into $5 \mathrm{ml}$ of seed medium and grown at $37^{\circ} \mathrm{C}$ overnight. From each overnight culture, $500 \mu \mathrm{l}$ was used to inoculate $50 \mathrm{ml}$ of fresh fermentation medium- 1 . These cultures were grown at $37^{\circ} \mathrm{C}$, and the cells were harvested at an early log phase corresponding to an $\mathrm{OD}_{600}$ of 0.4 . Total RNA was extracted using the MasterPure $^{\mathrm{TM}}$ RNA Purification Kit (Epicentre Technologies, Madison, WI, USA) from $1 \mathrm{ml}$ of the early log phase culture. cDNA synthesis and labeling were performed as described in the Affymetrix GeneChip E. coli Antisense Genome Array Technical Manual [35]. The resulting labeled cDNAs were hybridized to an Affymetrix E. coli antisense genome array. Patterns of hybridization were detected with an Affymetrix Genearray scanner 2500 (Affymetrix, Inc., Santa Clara, CA, USA). The raw data were analyzed using Microarray Analysis Suite version 5.0 (Affymetrix). Every E. coli open reading frame (ORF) was assayed by a set of perfect match (PM) and mismatch (MM) probe pairs. If the PM probe showed an intensity that was at least $200 \mathrm{U}$ higher than that of the MM probe, the probe pair was considered to be present [35]. An ORF was considered to be present with 95\% confidence if neighboring probe pairs within an ORF were present.

\section{Results \\ Construction of L-threonine-overproducing E. coli strains and L-threonine production}

The wild-type E. coli MG1655 and reduced-genome E. coli MDS42 were modified in a stepwise manner to overproduce L-threonine. First, we isolated the threonine operon of E. coli strain ATCC 21277, which contains a mutated version of the thrA gene (thrA*) that encodes threonine feedback-resistant aspartate kinase I and homoserine dehydrogenase I; a homoserine kinase-encoding gene $($ thr $B)$; and a threonine synthase-encoding gene (thrC). The isolated threonine operon, which was expressed under the control of a Tac promoter, was then inserted into the genomes of MG1655 and MDS42 to replace their wild-type threonine operons. Second, the lacI gene, which encodes the E. coli LacI transcriptional repressor, was deleted so that the mutant threonine operon would be expressed constitutively. The resulting strains, MG-102 and MDS-202, produced 34.06 and $36.61 \mathrm{mg} / \mathrm{L}$ of L-threonine, respectively (Fig. 2).

Third, the $t d h$ gene, which encodes threonine dehydrogenase, was deleted from MG-102 and MDS-202 to prevent the degradation of L-threonine, generating strains MG103 and MDS-203, which produced 42.25 and $79.94 \mathrm{mg} /$ L of L-threonine, respectively (Fig. 2). Finally, to enhance the export of L-threonine into the culture media and block re-uptake, we sequentially replaced the $t d c C$ gene, which encodes the threonine STP importer [36], and the sstT gene, which encodes the DctA dicarboxylate (DAACS) importer [37], in MG-103 and MDS-203 with a mutant threonine exporter gene (rhtA23). The resulting strains, MG-105 and MDS-205, produced 165.54 and $303.23 \mathrm{mg} /$ L of L-threonine, respectively (Fig. 2). These final strains showed an 10- and 15.5-fold increase in L-threonine production, compared to their parental strains, MG1655 and MDS42, respectively (Fig. 2).

When a batch-fermentation was carried out, the final strain MDS-205 produced $40.1 \mathrm{~g} / \mathrm{L}$ of L-threonine (a yield of $0.401 \mathrm{~g}$ threonine/g glucose) after $30 \mathrm{~h}$ of fermentation.

\section{Comparative transcriptome analysis of MG-105 and MDS- 205 using DNA microarrays}

To understand the difference in global gene expression levels in MG-105 and MDS-205, a transcriptional profiling experiment was performed. One hundred genes $(2.7 \%$ of the total genes expressed) in MDS-205 cells were differentially expressed by more than 2-fold compared to MG105 cells (63 up-regulated and 37 down-regulated) (Additional file 2). Genome-scale gene expression analysis of MG-105 and MDS-205 revealed that the most of the genes related to the central metabolism and L-threonine biosynthesis were up-regulated in MDS-205. The expression ratios of genes related to central metabolic pathways and L-threonine biosynthesis are shown in Fig. 3. The expression levels of the $p t s G$ gene involved in the glucose PTSsystem was down-regulated by 0.80 -fold in MDS-205, whereas genes involved in the non-PTS glucose uptake system, $m g l A B C$ and $g l k$, were up-regulated by 1,61-, 1.38, 1.32- and 1.30-fold, respectively. In addition, the tktAB genes involved in the pentose phosphate shunt were upregulated by 1.54-, and 1.63-fold in MDS-205, respectively. And the pck gene involved in the carboxylation of phosphoenolpyruvate was up-regulated by 1.22 -fold in MDS-205. Meanwhile genes involved in the mixed acid fermentation ( $p \circ x B$, pta, and $a d h E$ ) were down-regulated in MDS-205. The aspC gene, which products directs oxaloacetate toward L-threonine biosyntheis, the glcB gene involved in the glyoxylate-shunt, and genes involved in TCA cycle were also up-regulated in MDS-205. The thrABC genes involved in L-threonine biosynthesis and 


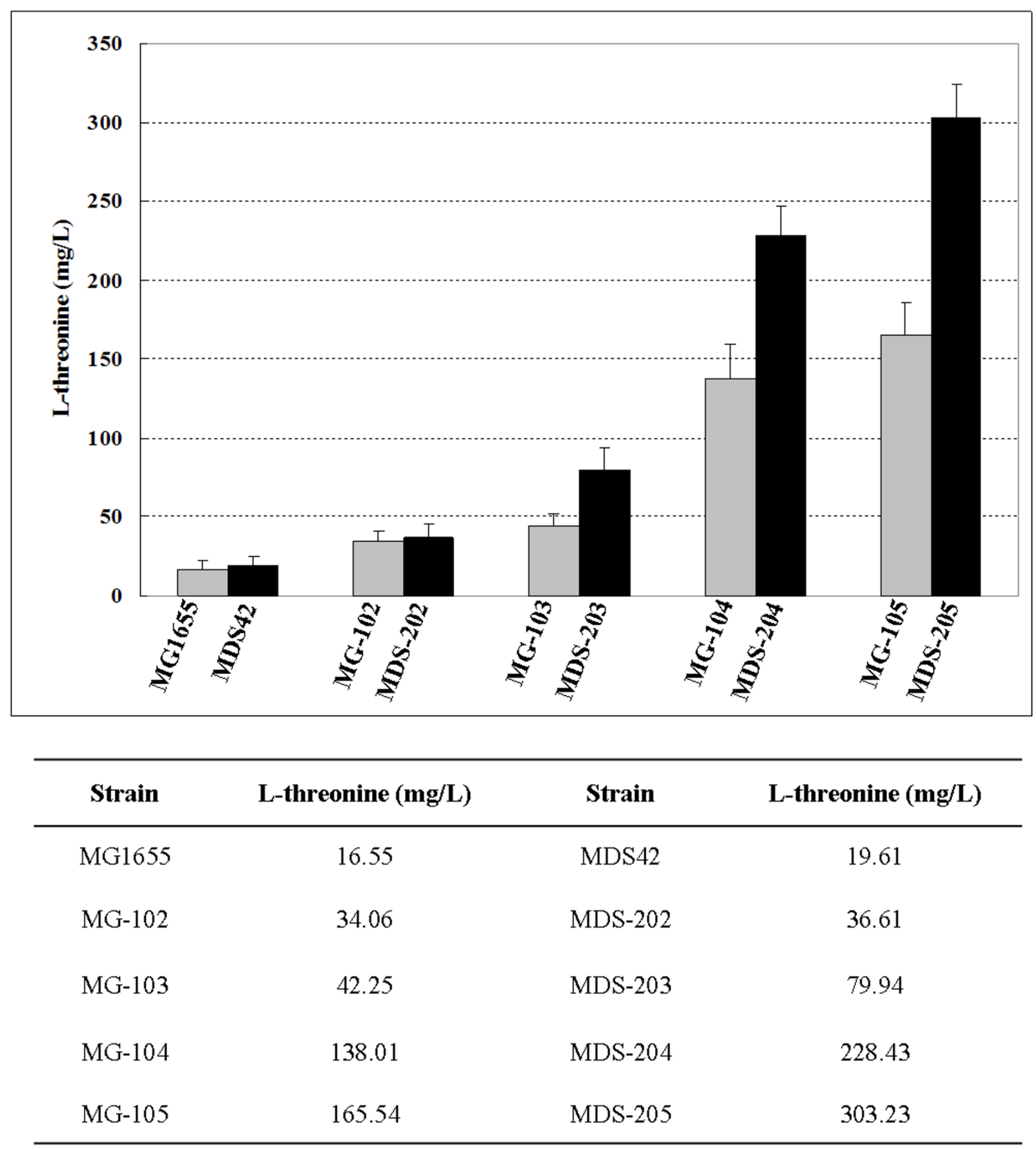

Figure 2

Production of L-threonine by constructed strains. The strains were cultivated in $50 \mathrm{ml}$ of fermentation medium- $\mathrm{I}$ at $37^{\circ} \mathrm{C}$ (refer to Materials and Methods). After $24 \mathrm{~h}$ of cultivation, the L-threonine concentration in the culture broth was measured by our bioassay system (refer to Materials and Methods). The data shown are the means and standard deviations for three independent experiments. 


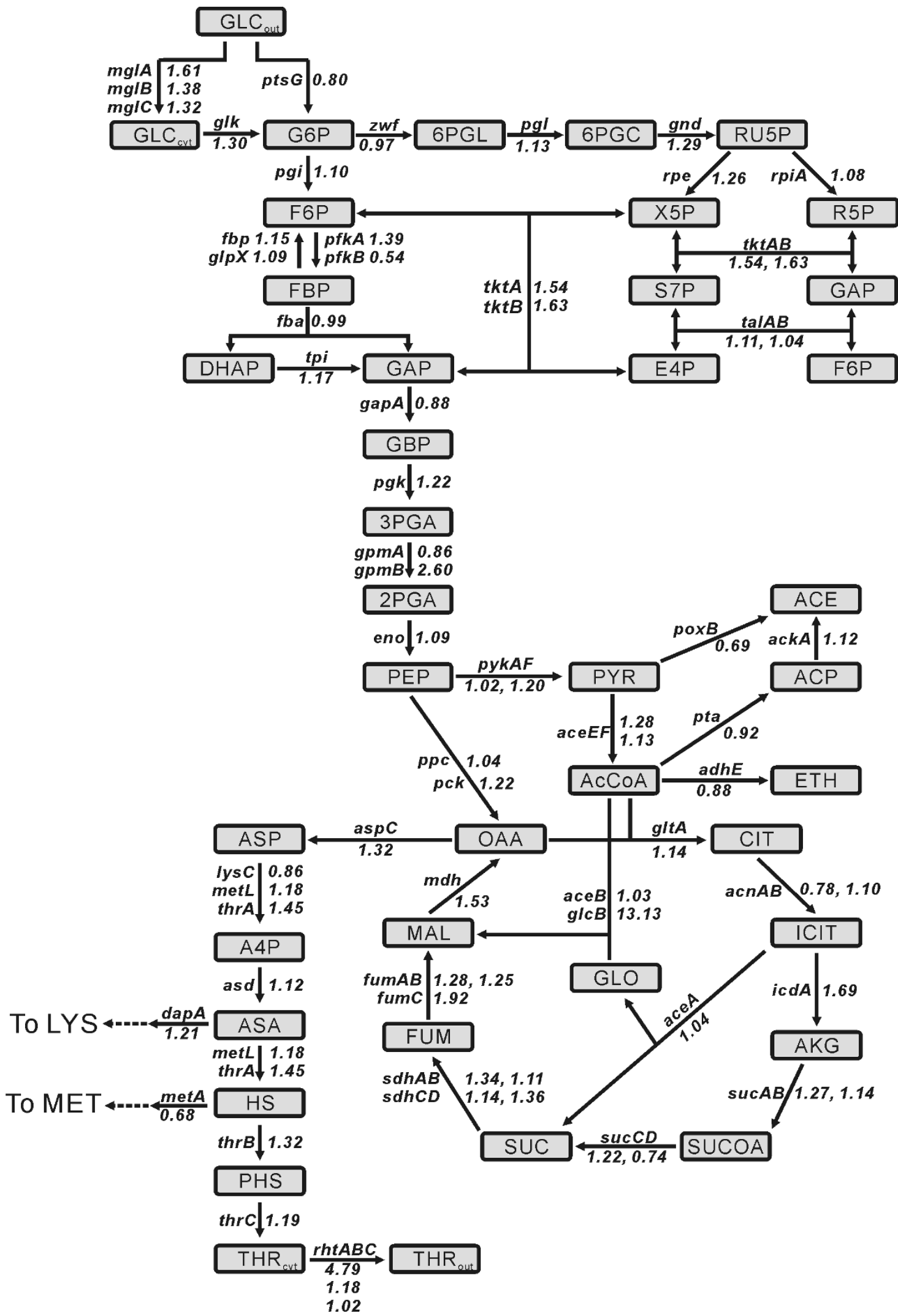

Figure 3 (see legend on next page) 
Figure 3 (see previous page)

Relative transcriptional levels of genes related to central metabolism for L-threonine producing strain MG-I 05 and MDS-205. Metabolic networks showing the relative transcriptional levels of genes related to the central metalbolism, mixed acid fermentation and L-threonine biosysnthetic pathways. The numbers are the relative ratio of the expression level of MDS-205 as compared to that of MG-105. Metabolite abbreviations: GLC out $_{\text {, glucose in medium; GLC }}$ cyt, glucose in cytoplasm; G6P, glucose-6-phosphate; F6P, fructose-6-phosphate; FBP, fructose-I,6-bisphosphate; DHAP, dihydroxyacetonephosphate; GAP, glyceraldehyde-3-phosphate; GBP, I,3-bisphosphoglycerate; 3PGA, 3-phosphoglycerate; 2PGA, 2-phosphoglycerate; PEP, phosphoenolpyruvate; PYR, pyruvate; AcCoA, acetyl-CoA; ACP, acetyl-phosphate; ACE, acetate; ETH, ethanol; OAA, oxaloacetate; CIT, citrate; ICIT, isocitrate; AKG, a-ketoglutarate; SUCOA, succinyl-CoA; SUC, succinate; FUM, fumarate; MAL, malate; ASP, aspartate; A4P, aspartyl-4-phosphate; ASA, aspartate semialdehyde; HS, homoserine; PHS, homoserine phosphate; $\mathrm{THR}_{\text {out }}$, L-threonine in medium; THR ${ }_{\text {cyt }}$, L-threonine in cytoplasm; 6PGL, gluconolactone-6-phosphate; 6PGC, 6-phosphogluconate; RU5P, ribulose-5-phosphate; X5P, xylurose-5-phosphate; R5P, ribose-5-phosphate; S7P, sedoheptulose-7-phosphate; E4P, erythrose-4-phosphate.

the $r h t A$ gene responsible for the L-threonine export were up-regulated by 1.45-, 1.32-, 1.19-, and 4.79-fold, respectively, in MDS-205.

\section{Discussion}

The restructuring of microbial genomes by eliminating genes that are unnecessary for a cellular metabolism has received special attention as an important strategy for industrial strain improvement [1-5]. Recently, scientists reported on the advantages of the reduced-genome E. coli strain MDS42 and its applications for bioindustry [5,38]. The MDS42 genome is $14.3 \%$ smaller than that of the wild-type strain MG1655 and has 700 fewer genes.

In this study, we compared the metabolic efficiency of Lthreonine production in the wild-type E. coli strain MG1655 and reduced-genome E. coli strain MDS42 by introducing into each of these strains a series of genetic modifications that altered L-threonine production, degradation, export into the media, and re-uptake from the media. These modifications gave rise finally to MG-105 (from MG1655) and MDS-205 (from MDS42). Although both MG1655 and MDS42 went through the same modifications, the threonine production of MDS-205 strain was an 2-fold greater than that of the MG-105 strain.

Genome-scale gene expression analysis of MG-105 and MDS-205 revealed that the most of the genes involved in the central metabolism and L-threonine biosynthesis were up-regulated in MDS-205. Among the up-regulated genes, the expression level of the rhtA threonine exporter gene was increased by 4.79-fold in MDS-205. This result indicates that the maximization of L-threonine export combined with deletion of the $t d c C$ and sst $T$ gene involved in the re-uptake of L-threonine across the membrane is one of the important steps for the mass production of L-threonine from $E$. coli. An additional advantage of the overexpression of the rhtA gene is that it increases the tolerance of E. coli to L-threonine by an 3-fold [31], which helps the E. coli to withstand high concentrations of L-threonine in the media. This adaptation also might contribute to the higher L-threonine production.

The up-regulation of the ATP-dependent glucose transport and phosphorylation system ( $m g l A B C$ and glk genes) and down-regulation of the PTS system (ptsG gene) in MDS205 may increase the availability of the phosphoenolpyruvate (PEP) which is a precursor of oxaloacetate (OAA) and aspartate. This result is consistent with the prediction based on flux balance analyses of gene knock-outs in an E. coli metabolic model that the replacement of PTS activity by an ATP-dependent glucose transport system should increase aspartate-family amino acids [39,40]. In addition, down-regulation of poxB, pta, and adhE genes, which are directing PEP to acetate and ethanol, may reduce the PEP flux to acetate and ethanol and further increase the PEP availability.

It is also reported that the up-regulation of $p c k$ gene involved in the carboxylation of PEP to OAA leads to increased cellular growth and biomolecular production, since the $p p c$ reaction releases an inorganic phosphate, in contrast to the $p c k$ reaction, which produces a high-energy ATP [41-44]. The effect of the pentose phosphate shunt and glyoxylate bypass on the glycolytic flux to L-threonine production also has been reported [45]. Therefore, the upregulation of the $p c k$ gene involved in the PEP carboxylation and $t k t A B$ genes involved in the pentose phosphate shunt and the increased expression of the genes involved in TCA cycle and the glyoxylate bypass ( $m d h$, fumABC, $s d h A B C D$, and $g l c B$ genes) may increase the OAA synthesis in MDS-205, resulted in higher production of L-threonine in MDS-205 compared to MG-105. The increased PEP and OAA level of MDS-205 by increasing the non-PTS glucose uptake system, PEP carboxylation, the pentose phosphate pathway, and the glyoxylate shunt, and reducing the mixed acid fermentation may resulted in increased production of L-threonine. 


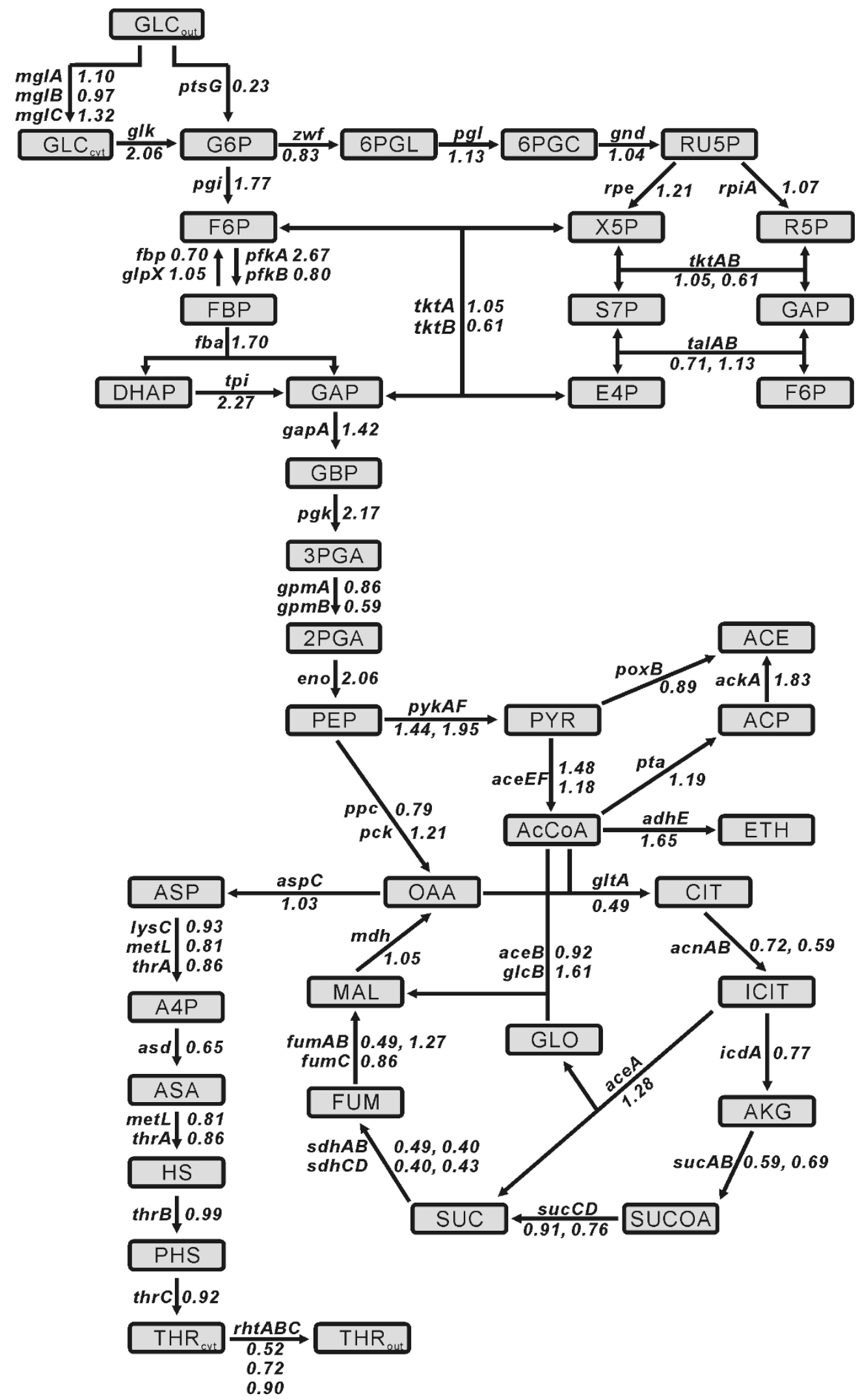

Figure 4 (see legend on next page) 
Figure 4 (see previous page)

Relative transcriptional levels of genes related to central metabolism for L-parental strain MG I655 and

MDS42. Metabolic networks showing the relative transcriptional levels of genes related to the central metalbolism, mixed acid fermentation and L-threonine biosysnthetic pathways. The numbers are the relative ratio of the expression level of MDS42 as

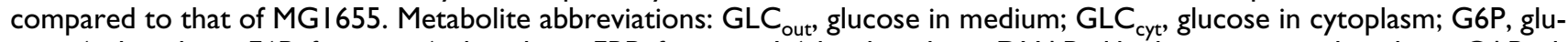
cose-6-phosphate; F6P, fructose-6-phosphate; FBP, fructose-I,6-bisphosphate; DHAP, dihydroxyacetonephosphate; GAP, glyceraldehyde-3-phosphate; GBP, I,3-bisphosphoglycerate; 3PGA, 3-phosphoglycerate; 2PGA, 2-phosphoglycerate; PEP, phosphoenolpyruvate; PYR, pyruvate; AcCoA, acetyl-CoA; ACP, acetyl-phosphate; ACE, acetate; ETH, ethanol; OAA, oxaloacetate; CIT, citrate; ICIT, isocitrate; AKG, a-ketoglutarate; SUCOA, succinyl-CoA; SUC, succinate; FUM, fumarate; MAL, malate; ASP, aspartate; A4P, aspartyl-4-phosphate; ASA, aspartate semialdehyde; HS, homoserine; PHS, homoserine phosphate; $\mathrm{THR}_{\text {out }}$, L-threonine in medium; THR ${ }_{\text {cyt }}$, L-threonine in cytoplasm; 6PGL, gluconolactone-6-phosphate; 6PGC, 6-phosphogluconate; RU5P, ribulose-5-phosphate; X5P, xylurose-5-phosphate; R5P, ribose-5-phosphate; S7P, sedoheptulose-7-phosphate; E4P, erythrose-4-phosphate.

The increased productivity of L-threonine in MDS42 might also result from a decrease in the metabolic burden due to the genome reduction. It is well known that the maintenance and expression of unnecessary genes, such as plasmid DNA, impose an uncharacterized metabolic burden on the bacterial host [46]. The metabolic burden could arise due to the extra biosynthetic demands for synthesis and expression of unnecessary genes [47,48], or the perturbation of the $E$. coli host regulatory system affecting central metabolic pathways $[46,49]$. The genome-scale gene expression analysis of the wild-type MG1655 and the MDS42 revealed that the genes involved in the non-PTS glucose uptake system and glycolysis were up-regulated in MDS42 compared to MG1655, whereas the genes involved in the glucose PTS-system and TCA cycle were down-regulated in MDS42 compared to MG1655 (Fig 4). It seems that the elimination of unnecessary genes from the E. coli genome might lead to more efficient cellular metabolism and an improved substrate yield coefficient, resulting in nutrient and energy saving of cells without physiological compromise. Researchers reported that the elimination of unnecessary genes actually improves $E$. coli robustness and enhances carbon metabolism [5,38,50]. In fact, genes involved in mixed acid fermentation were up-regulated in MDS42 compared to MG1655 (Fig 4), leading to the acetate accumulation which indicates a carbon-overflow metabolism [13]. Therefore, the increased production of L-threonine in MDS-205 might be resulted from the redirection of the overflowed carbon metabolism in MDS42 caused by elimination of unnecessary genes from the E. coli genome into the production of Lthreonine.

\section{Conclusion}

In this study, we report the results of a reengineering of MDS42 to increase production of the amino acid L-threonine, which is essential for growth and maintenance of commercial livestock [25]. Even though a series of systematic experiments is needed for better understanding of the mechanism underlying the higher L-threonine produc- tion in the reduced-genome E. coli MDS42, our results described herein clearly indicate that MDS42 can serve as an efficient host strain for the production of other useful biomaterials.

\section{Competing interests}

The authors declare that they have no competing interests.

\section{Authors' contributions}

JL and BS carried out the construction and analysis of the threonine producing strains. BY and JK participated in the fermentation study. FB participated in the genome-scale transcriptional analysis. MK, and SK helped to draft the manuscript. All authors read and approved the final manuscript.

\section{Additional material}

\section{Additional file 1}

Table S1. List of all primers used in this study.

Click here for file

[http://www.biomedcentral.com/content/supplementary/14752859-8-2-S1.doc]

\section{Additional file 2}

Table S2. List of all genes that were differentially expressed in MDS205 , relative to $M G-105$.

Click here for file

[http://www.biomedcentral.com/content/supplementary/1475-

2859-8-2-S2.doc]

\section{Acknowledgements}

This work was supported in part by grants from 2IC Frontier Program of Microbial Genomics and Applications (MG08-0204-I-0), the Research Program of New Drug Target Discovery (MI07482223 I4-08N4800-3 I 4I0) from the Ministry of Education, Science and Technology, the Korea Science and Engineering Foundation Grant (ROI-2008-000-20559-0), and the Korea Research Foundation Grant (KRF-2004-042-D00072). 


\section{References}

I. Ara K, Ozaki K, Nakamura K, Yamane K, Sekiguchi J, Ogasawara N: Bacillus minimum genome factory: effective utilization of microbial genome information. Biotechnol Appl Biochem 2007, 46: $169-178$.

2. Fujio T: Minimum genome factory: innovation in bioprocesses through genome science. Biotechnol Appl Biochem 2007, 46: $145-146$.

3. Giga-Hama Y, Tohda H, Takegawa K, Kumagai H: Schizosaccharomyces pombe minimum genome factory. Biotechnol Appl Biochem 2007, 46: I47-I55.

4. Mizoguchi $\mathrm{H}$, Mori $\mathrm{H}$, Fujio T: Escherichia coli minimum genome factory. Biotechnol Appl Biochem 2007, 46:I57-I67.

5. Posfai G, Plunkett G 3rd, Feher T, Frisch D, Keil GM, Umenhoffer K, Kolisnychenko V, Stahl B, Sharma SS, de Arruda M, Burland V, Harcum SW, Blattner FR: Emergent properties of reduced-genome Escherichia coli. Science 2006, 31 2:1044-1046.

6. Gil R, Silva FJ, Pereto J, Moya A: Determination of the core of a minimal bacterial gene set. Microbiol Mol Biol Rev 2004, 68:518-537.

7. Koonin EV: Comparative genomics, minimal gene-sets and the last universal common ancestor. Nat Rev Microbiol 2003, I: $127-136$.

8. Koonin EV: How many genes can make a cell: the minimalgene-set concept. Annu Rev Genomics Hum Genet 2000, I:99-I I 6.

9. Mushegian A: The minimal genome concept. Curr Opin Genet Dev |999, 9:709-7|4

10. Arbabi-Ghahroudi M, Tanha J, MacKenzie R: Prokaryotic expression of antibodies. Cancer Metastasis Rev 2005, 24:50I-5I 9.

II. Ikeda M: Amino acid production processes. Adv Biochem Eng Biotechnol 2003, 79: I-35.

12. Jana S, Deb JK: Strategies for efficient production of heterologous proteins in Escherichia coli. Appl Microbiol Biotechnol 2005, 67:289-298.

13. Lee SY: High cell-density culture of Escherichia coli. Trends Biotechnol 1996, 14:98-105.

14. Terpe K: Overview of bacterial expression systems for heterologous protein production: from molecular and biochemical fundamentals to commercial systems. Appl Microbiol Biotechnol 2006, 72:21 I-222.

I5. Blattner FR, Plunkett G 3rd, Bloch CA, Perna NT, Burland V, Riley M, Collado-Vides J, Glasner JD, Rode CK, Mayhew GF, Gregor J, Davis NW, Kirkpatrick HA, Goeden MA, Rose DJ, Mau B, Shao Y: The complete genome sequence of Escherichia coli K-I2. Science 1997 , 277:|453-|474.

16. Andersen DC, Krummen L: Recombinant protein expression for therapeutic applications. Curr Opin Biotechnol 2002, I 3: I I 7-I 23.

17. Andersen DC, Swartz J, Ryll T, Lin N, Snedecor B: Metabolic oscillations in an Escherichia coli fermentation. Biotechnol Bioeng 2001, 75:212-218

18. Baneyx F: Recombinant protein expression in Escherichia coli. Curr Opin Biotechnol 1999, 1 0:4 I I-421.

19. Baneyx F, Mujacic M: Recombinant protein folding and misfolding in Escherichia coli. Nat Biotechnol 2004, 22: | 399-| 408.

20. Cebolla A, Royo JL, De Lorenzo V, Santero E: Improvement of recombinant protein yield by a combination of transcriptional amplification and stabilization of gene expression. Appl Environ Microbiol 2002, 68:5034-504I.

21. Chen Y, Song J, Sui SF, Wang DN: DnaK and DnaJ facilitated the folding process and reduced inclusion body formation of magnesium transporter CorA overexpressed in Escherichia coli. Protein Expr Purif 2003, 32:221-231.

22. Chevalet L, Robert A, Gueneau F, Bonnefoy JY, Nguyen T: Recombinant protein production driven by the tryptophan promoter is tightly controlled in ICONE 200, a new genetically engineered Escherichia coli mutant. Biotechnol Bioeng 2000, 69:35I-358.

23. Chou CH, Bennett GN, San KY: Genetic manipulation of stationary-phase genes to enhance recombinant protein production in Escherichia coli. Biotechnol Bioeng 1996, 50:636-642.

24. Diaz-Ricci JC, Regan L, Bailey JE: Effect of alteration of the acetic acid synthesis pathway on the fermentation pattern of Escherichia coli. Biotechnol Bioeng 1991, 38:1318-1324.

25. Debabov VG: The threonine story. Adv Biochem Eng Biotechnol 2003, 79:1 13-136.
26. Datsenko KA, Wanner BL: One-step inactivation of chromosomal genes in Escherichia coli K-I 2 using PCR products. Proc Natl Acad Sci USA 2000, 97:6640-6645.

27. Posfai G, Kolisnychenko V, Bereczki Z, Blattner FR: Markerless gene replacement in Escherichia coli stimulated by a doublestrand break in the chromosome. Nucleic Acids Res 1999, 27:4409-44I5.

28. Sung BH, Lee CH, Yu BJ, Lee JH, Lee JY, Kim MS, Blattner FR, Kim SC: Development of a biofilm production-deficient Escherichia coli strain as a host for biotechnological applications. Appl Environ Microbiol 2006, 72:3336-3342.

29. Patte JC: Biosynthesis of threonine and lysine. In Escherichia coli and Salmonella thyphimurium Volume I. 2nd edition. Edited by: Neidhardt FC. Washington DC: ASM; 1996:528.

30. Shiio I, Nakamori S, Sano K: US Patent 197I.

31. Livshits VA, Zakataeva NP, Aleshin VV, Vitushkina MV: Identification and characterization of the new gene rht $A$ involved in threonine and homoserine efflux in Escherichia coli. Res Microbiol 2003, I 54:123-135.

32. Yu BJ, Sung BH, Koob MD, Lee CH, Lee JH, Lee WS, Kim MS, Kim SC: Minimization of the Escherichia coli genome using a Tn5targeted Cre/loxP excision system. Nat Biotechnol 2002, 20:1018-1023.

33. Erickson AM, Diaz IB, Kwon YM, Ricke SC: A bioluminescent Escherichia coli auxotroph for use in an in vitro lysine availability assay. J Microbiol Methods 2000, 40:207-2I 2 .

34. Joseph $\mathrm{MH}$, Marsden CA: Amino acids and small peptides. In HPLC of Small Molecules, a Practical Approach Edited by: Lim CK. Oxford: IRL Press; 1986: I3-28.

35. GeneChip ${ }^{\circledR} E$. coli antisense genome array technical manual [http://www.affymetrix.com/support/technical/manual.affx]

36. Sumantran VN, Schweizer HP, Datta P: A novel membrane-associated threonine permease encoded by the $t d c C$ gene of Escherichia coli. J Bacteriol I990, I 72:4288-4294.

37. Kim YM, Ogawa W, Tamai E, Kuroda T, Mizushima T, Tsuchiya T: Purification, reconstitution, and characterization of $\mathrm{Na}(+)$ / serine symporter, SstT, of Escherichia coli. J Biochem 2002, I32:7|-76.

38. Sharma SS, Blattner FR, Harcum SW: Recombinant protein production in an Escherichia coli reduced genome strain. Metab Eng 2007, 9:133-|4|.

39. Burgard AP, Maranas CD: Probing the performance limits of the Escherichia coli metabolic network subject to gene additions or deletions. Biotechnol Bioeng 200I, 74:364-375.

40. Gosset G: Improvement of Escherichia coli production strains by modification of the phosphoenolpyruvate:sugar phosphotransferease system. Microb Cell Fact 2005, I 6: I4.

4I. Lee SJ, Lee DY, Kim TY, Kim BH, Lee J, Lee SY: Metabolic engineering of Escherichia coli for enhanced production of succinic acid, based on genome comparison and in silico gene knockout simulation. Appl Environ Microbiol 2005, 7 I:7880-7887.

42. Kim P, Laivenieks M, Vieille C, Zeikus JG: Effect of overexpression of Actinobacillus succinogenes phosphoenolpyruvate carboxykinase on succinate production in Escherichia coli. Appl Environ Microbiol 2004, 70: I 238-I24I.

43. Kwon YD, Lee SY, Kim P: Influence of gluconeogenic phosphoenolpyruvate carboxykinase (PCK) expression of succinic acid fermentation in Escherichia coli under high bicarbonate condition. J Microbiol Biotechnol 2006, I 6: |448-| 452.

44. Kwon YD, Lee SY, Kim P: A physiology study of Escherichia coli overexpressing phosphoenolpyruvate carboxykinase. Biosci Biotechnol Biochem 2008, 72: I |38-I|4I.

45. Lee KH, Park JH, Kim TY, Kim HU, Lee SY: Systems metabolic engineering of Escherichia coli for L-threonine production. Mol Syst Biol 2008, 3:149.

46. Diaz-Ricci JC, Hernandez ME: Plasmid effects on Escherichia coli metabolism. Crit Rev Biotechnol 2000, 20:79-108.

47. Bremer $\mathrm{H}$, Dennis PP: Modulation of chemical composition and other parameters of the cells by growth rate. In Escherichia coli and Salmonella Volume 2. 2nd edition. Edited by: Neidhardt FC. Washington DC: ASM press; 1996: I553-1569.

48. Bonomo J, Gill RT: Amino acid content of recombinant proteins influences the metabolic burden response. Biotechnol Bioeng 2005, 90:116-126. 
49. Diaz-Ricci JC, Bode J, Rhee Jl, Schugerl K: Gene expression enhancement due to plasmid maintenance. J Bacteriol 1995, 177:6684-6687.

50. Kolisnychenko V, Plunkett G 3rd, Herring CD, Feher T, Posfai J, Blattner FR, Posfai G: Engineering a reduced Escherichia coli genome. Genome Res 2002, 12:640-647.

Publish with Bio Med Central and every scientist can read your work free of charge

"BioMed Central will be the most significant development for disseminating the results of biomedical research in our lifetime." Sir Paul Nurse, Cancer Research UK

Your research papers will be:

- available free of charge to the entire biomedical community

- peer reviewed and published immediately upon acceptance

- cited in PubMed and archived on PubMed Central

- yours - you keep the copyright

Submit your manuscript here:

http://www.biomedcentral.com/info/publishing_adv.asp
BioMedcentral 